\title{
Association between time to reperfusion and echocardiography assessed left ventricular filling pressure in patients with first ST-segment elevation myocardial infarction undergoing primary coronary intervention
}

\author{
Yacov Shacham, Arie Steinvil, Eran Leshem-Rubinow, \\ Eyal Ben Assa, Gad Keren, Arie Roth, Yan Topilsky \\ Department of Cardiology, Tel-Aviv Sourasky Medical Center affiliated to \\ the Sackler Faculty of Medicine, Tel-Aviv University, Tel-Aviv, Israel
}

\begin{abstract}
Background: Diastolic dysfunction and elevated left ventricular (LV) filling pressure following acute myocardial infarction are associated with adverse outcomes. Although time to reperfusion is a powerful prognostic marker following acute myocardial infarction, little is known about its impact on diastolic function and LV filling pressure. We hypothesized that delayed time to reperfusion will be associated with worse diastolic function.

Methods: This study included 180 consecutive patients with first ST elevation myocardial infarction (STEMI) treated by primary percutaneous coronary intervention (PCI). They presented of chest pain within 24 h and underwent echocardiography within 3 days of primary PCI. Results: Median time to reperfusion, defined as the time from symptom onset to reperfusion at the end of primary PCI, was 185 min (interquartile range 120-660). Patients with reperfusion time $>185 \mathrm{~min}(n=92)$ had a significantly higher E/septal e' $(13.3 \pm 5.0$ vs. $9.7 \pm 2.3$, $p<0.001)$ and E/lateral $e^{\prime}(9.8 \pm 3.5$ vs. $7.8 \pm 2.2, p<0.001)$ ratios, and more advanced diastolic grade $(p<0.001)$ compared to those having early reperfusion $(n=88)$. There were no significant differences in LV ejection fraction and left atrial volume between the two groups. Time to reperfusion was an independent predictor of early E/average e' ratio. The adverse effect of late reperfusion on diastolic dysfunction was more prominent in patients with anterior myocardial infarction.
\end{abstract}

Conclusions: Longer time to reperfusion is associated with early elevated LV diastolic pressure in primary PCI-treated patients with STEMI. (Cardiol J 2014; 21, 4: 357-363)

Key words: acute myocardial infarction, time to reperfusion, left ventricular filling pressure

Address for correspondence: Dr Yacov Shacham, Department of Cardiology, Tel Aviv Sourasky Medical Center, 6 Weizman Street, Tel Aviv 64239, Israel, tel: +972 3 6973222, fax: +972 3 6973704, e-mail: kobyshacham@gmail.com Received: 31.07.2013 Accepted: 28.08.2013

Drs. Shacham and Steinvil contributed equally to this work.

All authors take responsibility for all aspects of the reliability and freedom from bias of the data presented and their discussed interpretation. 


\section{Introduction}

Echocardiographic indices of elevated left ventricular (LV) filling pressures are associated with adverse remodeling, increased incidence of heart failure and worse survival following acute myocardial infarction (AMI) [1-4]. Doppler tissue imaging of mitral annulus velocity reflects the rate of change in LV long-axis dimension and volume, thus impaired relaxation results in a reduced early mitral annulus velocity (e'). Compared to other indicators of diastolic function, e' velocity is relatively independent of preload, especially when the rate of myocardial relaxation is decreased [5-7]. The ratio of early transmitral flow velocity (E) to early diastolic septal or lateral mitral annulus velocity (E/e') has been shown to be the most accurate noninvasive predictor of elevated LV filling pressure [5]. An elevated E/e' ratio, especially one $>15$, reportedly predicted poorer prognosis following MI [8, 9]. We evaluated the relation between time to reperfusion and the $\mathrm{E} / \mathrm{e}$ ' ratio in patients presenting with first ST-segment elevation MI (STEMI), who underwent successful reperfusion with primary percutaneous coronary intervention (PPCI). We hypothesized that longer time to reperfusion would be associated with an elevated $\mathrm{E} / \mathrm{e}$ ' ratio.

\section{Methods}

Our cohort included 265 consecutive patients with an acute STEMI, who were admitted to the cardiac intensive care unit (CICU) of the Tel-Aviv Sourasky Medical Center between May 2011 and January 2013, and underwent PPCI. The baseline demographic, clinical, echocardiographic and angiographic results were retrieved from medical files and the hospital database. Three patients who had severe valvular disease (1 with severe mitral regurgitation, and 2 with prosthetic valves), and 7 with a previous history of ischemic heart disease were excluded. We excluded all patients older than 75 years $(n=65)$ to avoid diastolic abnormalities that may be related to advanced age [10]. We excluded also 6 patients with severe hemodynamic instability (e.g., cardiogenic shock at admission defined as persistent systolic blood pressure $<90 \mathrm{~mm} \mathrm{Hg}$ and nonresponsive to fluid replacement, or the need for inotropes or intra-aortic balloon pumping to maintain blood pressure $\geq 90 \mathrm{~mm} \mathrm{Hg}$ ). Finally, 2 patients with no significant coronary lesions and 2 patients with failed reperfusion (defined as TIMI flow $<3$ at the end of PPCI) were also excluded because of inability to accurately measure "reperfusion time".
The diagnosis of STEMI was based on typical history of chest pain, diagnostic electrocardiographic changes, and serial elevation of serum cardiac biomarkers in all patients [11]. The electrocardiographic criterion for the diagnosis of STEMI was an ST-segment elevation of $\geq 1 \mathrm{~mm}$ in $>2$ adjacent leads. The patients were treated according to the discretion of the senior attending physician in the CICU. PPCI was performed in all patients irrespective of duration of symptoms. Angiographic coronary artery stenosis was defined as luminal diameter narrowing $\geq 70 \%$. Coronary artery blood flow was defined according to standardized thrombolysis in MI (TIMI) grades 0-3 [12]. A culprit artery was defined as one with an identifiable thrombotic lesion on an angiogram corresponding to electrocardiographic changes. Successful reperfusion was defined as $<30 \%$ residual stenosis and TIMI grade 3 flow. Time to reperfusion was defined as the time from symptom onset (usually chest pain or discomfort) recorded upon admission to the restoration of TIMI grade 3 flow in the infarct artery, as reported in the catheterization laboratory report.

All patients underwent a screening echocardiographic examination within 2-72 h from PPCI. Echocardiography was performed by Philips IE-33, GE and Vivid 3 models equipped with S5-1 transducers (Philips Healthcare, Andover, MA, USA). LV diameters and interventricular septal and posterior walls widths were measured from the parasternal short axis by means of a two-dimensional (2D), or a 2D-guided M-mode echocardiogram of the $\mathrm{LV}$ at the papillary muscle level, using the parasternal short-axis view [13]. LV ejection fraction (LVEF) was calculated by the Quinones method [13]. The 16 -segment model was used for scoring the severity of segmental wall motion abnormalities according to the American Society of Echocardiography [14]. Early transmitral flow velocity (E) and early diastolic mitral annular velocity (e') were measured in the apical 4-chamber view to provide an estimate of LV diastolic function [15]. The e' was measured from septal and lateral annulus. The ratio of peak $\mathrm{E}$ to peak e' (septal, lateral and average) was calculated (mitral E/e' ratio) from the average of at least 3 cardiac cycles. The deceleration time of the E-wave was also measured. Left atrial (LA) volume was calculated using the biplane area length method at end systole [16]. The cardiac output was calculated as the product of aortic stroke volume and heart rate, as demonstrated on pulse wave Doppler. Valvular regurgitation was qualitatively assessed using color Doppler according to the guidelines of the American Society of Echocardiography (normal/ 
/trivial $=1$, mild $=2$, moderate $=3$, severe $=4$ ) [17]. Diastolic function was assessed by integrating measurements of the mitral inflow, LA volume and Doppler tissue imaging of the mitral annulus, based on recent guidelines [15] and classified into four categories: normal diastolic function $=0$, impaired relaxation $=1$, pseudo-normal $=2$ and restrictive pattern $=3$ based on recent guidelines [15]. Right atrial (RA) pressure was estimated by the inferior vena cava (IVC) diameter as well as its response to inspiration, as previously described [18]. Briefly, expiratory and inspiratory IVC diameters and percent collapse were measured in subcostal views within $2 \mathrm{~cm}$ of the RA. IVC diameter $<2.1 \mathrm{~cm}$ that collapsed $>50 \%$ with a sniff suggested normal RA pressure (assigned as $5 \mathrm{~mm} \mathrm{Hg}$ ), whereas an IVC diameter $>2.1 \mathrm{~cm}$ that collapsed $<50 \%$ with a sniff suggested high RA pressure $(15 \mathrm{~mm} \mathrm{Hg})$. In patients with IVC diameter $<2.1 \mathrm{~cm}$ and no collapse $(<20 \%)$ with a sniff, RA pressure was upgraded to $20 \mathrm{~mm} \mathrm{Hg}$. In indeterminate cases in which the IVC diameter and collapse did not fit this paradigm, secondary indices of elevated RA pressure were integrated. If uncertainty remained, RA pressure was left as intermediate value of $10 \mathrm{~mm} \mathrm{Hg}$. Peak systolic pulmonary artery pressure was estimated using the modified Bernoulli formula $\left(4 \times \mathrm{TRVmax}^{2}\right)+\mathrm{RAP}$, where TRVmax is the peak systolic tricuspid regurgitation velocity at end expiration, and RAP is the RA pressure.

Troponin I assays were performed at admission and then at 12,24 and $48 \mathrm{~h}$ to determine enzymatic infarct size. Similarly, creatine kinase levels were measured serially at admission and then every $6 \mathrm{~h}$ until peak levels were reached.

The study was approved by the local committee and all patients gave their informed consent.

\section{Statistical analysis}

All data were summarized and displayed as mean ( \pm standard deviation) for continuous variables and as number (percentage) of patients in each group for categorical variables. The $\mathrm{p}$ values for the 2 test were calculated with Fisher's exact test. The $\mathrm{p}$ value for the $\mathrm{t}$-test is reported according to Levene's test for equality of variance. Linear regression models were performed at the ENTER mode where the dependant variable was defined as average E/e' and adjusted to age, gender, LVEF, history of diabetes, hypertension, peak creatine phosphokinase, and peak troponin and ischemia duration. All the analyses were considered significant at a 2 -tailed $\mathrm{p}$ value $<0.05$. The SPSS statistical package was used to perform all statistical evaluations (SSPS, Chicago, IL).

\section{Results}

A total number of 180 consecutive patients (mean age $56 \pm 9$ years, range $33-75,82 \%$ males) met the inclusion criteria of this study and their data were included in the analyses. The median total time to reperfusion was $185 \mathrm{~min}$ (interquartile range 120-660). Eighty-eight (49\%) patients had time to reperfusion $\leq 185 \mathrm{~min}$ and $92(51 \%)$ had time to reperfusion $>185 \mathrm{~min}$. Baseline echocardiograms were obtained $1.6 \pm 1.4$ days following admission. Table 1 presents clinical, laboratory and angiographic data of patients with time to reperfusion $\leq 185 \mathrm{~min}$ and $>185 \mathrm{~min}$. There were no significant differences between the groups in these parameters other than a greater prevalence of women, and higher C-reactive protein levels in the group with time to reperfusion $>185 \mathrm{~min}$. Table 2 displays the admission echocardiographic data of the two groups. Patients with time to reperfusion $>185 \mathrm{~min}$ had a significantly higher mean mitral inflow $\mathrm{E}$ wave velocity $(78 \pm 19$ vs. $68 \pm 16 \mathrm{~cm} / \mathrm{s}, \mathrm{p}=0.001)$, a lower septal e' velocity $(6.3 \pm 1.8$ vs. $7.3 \pm 1.8 \mathrm{~cm} / \mathrm{s}, \mathrm{p}=0.001)$, a higher $\mathrm{E} / \mathrm{septal}$ e' ratio (13.3 \pm 5.0 vs. $9.7 \pm 2.3$, $\mathrm{p}<0.001), \mathrm{E} /$ lateral e' ratio $(9.8 \pm 3.5$ vs. $7.8 \pm$ $\pm 2.2, \mathrm{p}<0.001)$, and $\mathrm{E} /$ average e' ratio $(11 \pm 3.6$ vs. $8.6 \pm 1.9, \mathrm{p}<0.001)$ than patients with time to reperfusion $\leq 185 \mathrm{~min}$. Distribution of diastolic function was significantly different between the groups, with $43 \%$ of the early reperfusion patients having normal diastolic function and $12 \%$ of them having grade 2 diastolic dysfunction (pseudo-normal pattern), compared to only $20 \%$ normal and $32 \%$ pseudo-normal diastolic function, in the late time to reperfusion group $(\mathrm{p}<0.001)$, respectively. There were no significant changes in LVEF, cardiac output, or LA volume between the groups. The changes in diastolic parameters were more prominent among patients having anterior MI $(n=87)$ and confined to septal e', E/septal e' and $\mathrm{E} /$ average $\mathrm{e}^{\prime}$ in patients with non-anterior $\mathrm{MI}$ (Table 3). In sub-group analysis performed in 114 patients, in whom echocardiography was performed within $24 \mathrm{~h}$ of PPCI, diastolic function was worse in patients with later reperfusion (Table 4). Linear logistic regression model incorporating predictors of average E/e' ratios, such as age, gender, LVEF, diabetes, hypertension, peak creatine phosphokinase, and peak troponin showed that time to reperfusion, hypertension and gender were the only independent predictors of $\mathrm{E} / \mathrm{e}$ ' ratio (Table 5). 
Table 1. Baseline characteristics of 180 consecutive patients presenting with first-ever ST elevation myocardial infarction.

\begin{tabular}{|c|c|c|c|}
\hline \multirow[t]{2}{*}{ Variable } & \multicolumn{2}{|c|}{ Time to reperfusion } & \multirow[t]{2}{*}{$P^{*}$} \\
\hline & $\leq 185 \min (n=88)$ & $>185 \min (n=92)$ & \\
\hline Age [years] & $56 \pm 9$ & $58 \pm 9$ & NS \\
\hline Men & $81(54 \%)$ & $68(46 \%)$ & 0.001 \\
\hline Diabetes mellitus & $9(10 \%)$ & $16(17 \%)$ & NS \\
\hline Dyslipidemia & $38(43 \%)$ & $34(37 \%)$ & NS \\
\hline Hypertension & $27(31 \%)$ & $34(37 \%)$ & NS \\
\hline Smoker & $55(62 \%)$ & $58(63 \%)$ & NS \\
\hline Family history of coronary artery disease & $20(23 \%)$ & $22(24 \%)$ & NS \\
\hline \multicolumn{4}{|l|}{ Number of narrowed coronary arteries: } \\
\hline 1 & $49(56 \%)$ & $36(39 \%)$ & NS \\
\hline 2 & $26(30 \%)$ & $31(34 \%)$ & NS \\
\hline 3 & $13(14 \%)$ & $25(27 \%)$ & NS \\
\hline Proximal infarct related artery narrowing & $46(52 \%)$ & $50(54 \%)$ & NS \\
\hline Pre-angioplasty TIMI flow 0 & $54(62 \%)$ & $60(65 \%)$ & NS \\
\hline Anterior infarct location & $44(50 \%)$ & $43(47 \%)$ & NS \\
\hline Time to reperfusion [min] & $134 \pm 28$ & $643 \pm 500$ & $<0.001$ \\
\hline Time to echocardiogram [days] & $1.65 \pm 1.5$ & $1.6 \pm 1.3$ & NS \\
\hline Peak creatine kinase [IU/L] & $1453 \pm 1538$ & $1548 \pm 1668$ & NS \\
\hline Peak troponin $[\mathrm{ng} / \mathrm{mL}]$ & $48 \pm 61$ & $48 \pm 61$ & NS \\
\hline$C$ reactive protein $[\mathrm{mg} / \mathrm{L}]$ & $6.1 \pm 10.6$ & $19.4 \pm 30.8$ & $<0.001$ \\
\hline
\end{tabular}

*The $\mathrm{p}$ values for the $\chi^{2}$ test were calculated with the Fisher's exact test. The $\mathrm{p}$ value for the t-test is reported following Levene's test for equality of variance; non-significant (NS) indicates 2-tailed non-significance ( $>0.05)$; TIMI — thrombolysis in myocardial infarction

\section{Discussion}

The principal finding of the current study is that longer time to reperfusion in patients with STEMI is associated with immediate worsening of diastolic function and elevated LV filling pressure, independent of LV systolic function or cardiac output. The elevated LV filling pressure combined with preserved cardiac output suggests that even a small delay in reperfusion $(>3 \mathrm{~h}$ ) leads to changes in the Frank-Starling curves of the ischemic/stunned heart, resulting in maintained cardiac output and ejection fraction at the price of increasing filling pressures.

Time to reperfusion is a known powerful prognostic marker in AMI patients undergoing reperfusion $[9,19,20]$ and major consideration is given to minimizing ischemic duration in order to improve survival following AMI [21]. Time to reperfusion is known to determine infarct size [22, 23] and systolic function [23] but there are only a few studies regarding its effect on diastolic function and filling pressure [24]. Prasad et al. [24] demonstrated that delayed reperfusion after STEMI was associated with increased prevalence of severe LV diastolic dysfunction and lower LVEF. However, in that report, patients with a restrictive pattern also had worse systolic dysfunction and significantly higher LA volume, suggesting that the reported restrictive physiologic changes may have been related to systolic dysfunction or to chronic diastolic dysfunction rather than to the acute event [25, 26].

Unlike previous studies, where diastolic dysfunction and evidence of elevated filling pressure (elevated $\mathrm{E} / \mathrm{e}$ ' ratio) following AMI were associated with reduced LV systolic function [8, 24] no such relation was found among our patients, possibly because all patients had undergone PPCI, thus systolic dysfunction was rare in both groups. The elevation in $\mathrm{E}$ and $\mathrm{E} / \mathrm{e}$ ' ratio in patients with longer ischemia duration was not associated with any difference in the ratio between early $(\mathrm{E})$ and late (atrial, A) ventricular filling velocity (the E/A ratio) because the distribution of diastolic function was mostly normal in the early reperfusion group, as opposed to largely pseudo-normal in the late reperfusion group. The differences in systolic pulmonary artery pressure between the early and late reperfusion groups did not reach statistical 
Table 2. Echocardiographic data of 180 consecutive patients presenting with first-ever ST elevation myocardial infarction.

\begin{tabular}{|c|c|c|c|}
\hline \multirow[t]{2}{*}{ Variable } & \multicolumn{2}{|c|}{ Time to reperfusion } & \multirow[t]{2}{*}{$\mathbf{P}^{*}$} \\
\hline & $\leq 185 \min (n=88)$ & $>185 \min (n=92)$ & \\
\hline Biplane left ventricular ejection fraction & $48 \pm 8$ & $47 \pm 8$ & NS \\
\hline Heart rate [bpmin] & $72 \pm 10$ & $76 \pm 12$ & NS \\
\hline Systolic blood pressure [mm Hg] & $136 \pm 20$ & $136 \pm 17$ & NS \\
\hline Diastolic blood pressure [mm Hg] & $81 \pm 13$ & $81 \pm 12$ & NS \\
\hline Cardiac output [L/min] & $5.1 \pm 1.0$ & $5.3 \pm 1.2$ & NS \\
\hline Diastolic grade [\%] & $\begin{array}{l}\text { Normal (43); Grade I (38) } \\
\text { Grade II (12); Grade III (7) }\end{array}$ & $\begin{array}{l}\text { Normal (20); Grade I (42) } \\
\text { Grade II (32); Grade III (7) }\end{array}$ & $<0.001$ \\
\hline Left atrial volume $[\mathrm{mL}]$ & $62 \pm 16$ & $61 \pm 17$ & NS \\
\hline Left atrial volume index $\left[\mathrm{mL} / \mathrm{m}^{2}\right]$ & $32 \pm 8$ & $32 \pm 9$ & NS \\
\hline Mitral inflow E wave $[\mathrm{cm} / \mathrm{s}]$ & $68 \pm 16$ & $77 \pm 19$ & 0.001 \\
\hline Mitral inflow E/A ratio & $1.17 \pm 0.45$ & $1.15 \pm 0.44$ & NS \\
\hline Septal e' velocity $[\mathrm{cm} / \mathrm{s}]$ & $7.3 \pm 1.8$ & $6.3 \pm 1.8$ & $<0.001$ \\
\hline E wave velocity/septal e' & $9.7 \pm 2.3$ & $13.3 \pm 5.0$ & $<0.001$ \\
\hline Lateral e' velocity [cm/s] & $8.21 \pm 2.3$ & $8.6 \pm 2.8$ & NS \\
\hline E wave velocity/lateral e' & $9.3 \pm 2.5$ & $9.8 \pm 3.5$ & $<0.001$ \\
\hline Average e' velocity $[\mathrm{cm} / \mathrm{s}]$ & $7.8 \pm 2.2$ & $7.31 \pm 1.8$ & $<0.001$ \\
\hline E wave velocity/average $e^{\prime}$ & $8.6 \pm 1.9$ & $11 \pm 3.6$ & $<0.001$ \\
\hline Mitral E wave deceleration time [ms] & $180 \pm 43$ & $178 \pm 45$ & NS \\
\hline LV end diastolic dimension [mm] & $48 \pm 7.8$ & $47.1 \pm 11.7$ & NS \\
\hline LV end systolic dimension [mm] & $30.7 \pm 6.8$ & $30.8 \pm 9.4$ & NS \\
\hline Septal thickness [mm] & $10.9 \pm 1.7$ & $12.6 \pm 1.5$ & NS \\
\hline Posterior wall thickness [mm] & $10.2 \pm 2.4$ & $9.7 \pm 2.7$ & NS \\
\hline Systolic pulmonary artery pressure [mm Hg] & $28 \pm 7$ & $31 \pm 9$ & NS \\
\hline Right atrial pressure [mm Hg] & $5 \pm 2$ & $6 \pm 3$ & NS \\
\hline
\end{tabular}

*The $p$ values for the $\chi^{2}$ test were calculated with the Fisher's exact test. The $p$ value for the t-test is reported following Levene's test for equality of variance; non-significant (NS) indicates 2-tailed non-significance ( $p>0.05)$.

Table 3. Echocardiographic data according infarct location.

\begin{tabular}{|c|c|c|c|c|c|c|}
\hline \multirow[t]{3}{*}{ Variable } & \multicolumn{3}{|c|}{$\begin{array}{c}\text { Anterior } \\
\text { infarction }\end{array}$} & \multicolumn{3}{|c|}{$\begin{array}{c}\text { Non anterior } \\
\text { infarction }\end{array}$} \\
\hline & \multicolumn{2}{|c|}{ Time to reperfusion } & \multirow[t]{2}{*}{$\mathbf{P}$} & \multicolumn{2}{|c|}{ Time to reperfusion } & \multirow[t]{2}{*}{$\mathbf{P}$} \\
\hline & $\begin{array}{c}\leq 185 \mathrm{~min} \\
(\mathrm{n}=44)\end{array}$ & $\begin{array}{c}>185 \mathrm{~min} \\
(n=43)\end{array}$ & & $\begin{array}{c}\leq 185 \mathrm{~min} \\
(\mathrm{n}=44)\end{array}$ & $\begin{array}{c}>185 \mathrm{~min} \\
(\mathrm{n}=49)\end{array}$ & \\
\hline LV ejection fraction & $45 \pm 8$ & $43 \pm 6$ & NS & $51 \pm 7$ & $50 \pm 8$ & NS \\
\hline Cardiac output [L/min] & $4.6 \pm 1$ & $5.1 \pm 1$ & NS & $5.6 \pm 1$ & $5.5 \pm 1$ & NS \\
\hline Left atrial volume $\left[\mathrm{mL}^{3}\right]$ & $64 \pm 16$ & $61 \pm 17$ & NS & $60 \pm 16$ & $61 \pm 17$ & NS \\
\hline E wave velocity $[\mathrm{cm} / \mathrm{s}]$ & $66 \pm 15$ & $73 \pm 19$ & NS & $70 \pm 17$ & $81 \pm 18$ & 0.003 \\
\hline E/A ratio & $1.2 \pm 0.4$ & $1.1 \pm 0.4$ & NS & $1.2 \pm 0.5$ & $1.2 \pm 0.4$ & NS \\
\hline $\mathrm{e}^{\prime}$ septal $[\mathrm{cm} / \mathrm{s}]$ & $6.7 \pm 1.5$ & $5.7 \pm 1.4$ & 0.003 & $7.8 \pm 2.0$ & $6.7 \pm 2.0$ & 0.01 \\
\hline E/e' septal & $10.1 \pm 2.2$ & $13.4 \pm 4.8$ & $<0.001$ & $9.3 \pm 2.3$ & $13.2 \pm 5.2$ & $<0.001$ \\
\hline $\mathrm{e}^{\prime}$ lateral $[\mathrm{cm} / \mathrm{s}]$ & $9.0 \pm 2.2$ & $8.1 \pm 2.5$ & 0.01 & $9.5 \pm 2.8$ & $8.9 \pm 3.0$ & NS \\
\hline E/e' lateral & $7.7 \pm 1.9$ & $9.9 \pm 4.0$ & 0.001 & $7.9 \pm 2.4$ & $9.7 \pm 2.1$ & NS \\
\hline Average $\mathrm{e}^{\prime}[\mathrm{cm} / \mathrm{s}]$ & $7.5 \pm 2.3$ & $6.2 \pm 2.2$ & 0.008 & $8.0 \pm 2.7$ & $7.1 \pm 2.7$ & NS \\
\hline E/e' average & $8.7 \pm 1.7$ & $11.1 \pm 2.9$ & 0.001 & $8.5 \pm 2.1$ & $10.8 \pm 3.1$ & $<0.001$ \\
\hline Mitral E wave deceleration time [ms] & $167 \pm 36$ & $175 \pm 39$ & NS & $192 \pm 45$ & $180 \pm 50$ & NS \\
\hline LVEDD [mm] & $48 \pm 8$ & $47 \pm 12$ & NS & $47 \pm 8$ & $47 \pm 11$ & NS \\
\hline LVESD [mm] & $31 \pm 7$ & $31 \pm 10$ & NS & $30 \pm 6$ & $31 \pm 9$ & NS \\
\hline SPAP [mm Hg] & $27 \pm 6$ & $32 \pm 8$ & 0.004 & $29 \pm 7$ & $30 \pm 10$ & NS \\
\hline Right atrial pressure [mm Hg] & $5 \pm 2$ & $7 \pm 4$ & 0.03 & $5 \pm 2$ & $5 \pm 2$ & NS \\
\hline
\end{tabular}

LV — left ventricular; LVEDD — LV end-diastolic dimension; LVESD — LV end-systolic dimension; SPAP — systolic pulmonary artery pressure 
Table 4. Echocardiographic data of 114 patients with echocardiography performed within $24 \mathrm{~h}$ of primary percutaneous coronary intervention.

\begin{tabular}{|c|c|c|c|}
\hline \multirow[t]{2}{*}{ Variable } & \multicolumn{2}{|c|}{ Time to reperfusion } & \multirow[t]{2}{*}{$P^{*}$} \\
\hline & $\leq 185 \min (n=54)$ & $>185 \min (n=60)$ & \\
\hline Biplane LV ejection fraction & $47 \pm 7$ & $47 \pm 8$ & NS \\
\hline Heart rate $[\mathrm{bpm}]$ & $72 \pm 10$ & $75 \pm 11$ & NS \\
\hline Systolic blood pressure [mm Hg] & $137 \pm 20$ & $139 \pm 18$ & NS \\
\hline Diastolic blood pressure [mm Hg] & $80 \pm 12$ & $82 \pm 14$ & NS \\
\hline Cardiac output [L/min] & $5.1 \pm 1.3$ & $5.4 \pm 1.1$ & NS \\
\hline Left atrial volume [mL] & $64 \pm 16$ & $58 \pm 15$ & NS \\
\hline Left atrial volume index $\left[\mathrm{mL} / \mathrm{m}^{2}\right]$ & $33 \pm 8$ & $30 \pm 8$ & NS \\
\hline Mitral inflow E wave [cm/s] & $64 \pm 16$ & $78 \pm 20$ & 0.003 \\
\hline Mitral inflow E/A ratio & $1.15 \pm 0.46$ & $1.15 \pm 0.40$ & NS \\
\hline Septal e' velocity [cm/s] & $7.3 \pm 1.9$ & $6.4 \pm 1.7$ & 0.01 \\
\hline E wave velocity/septal $e^{\prime}$ & $9.6 \pm 2.0$ & $13.1 \pm 5.2$ & $<0.001$ \\
\hline Lateral e' velocity [cm/s] & $9.3 \pm 2.6$ & $9.1 \pm 2.9$ & NS \\
\hline E wave velocity/lateral e' & $7.8 \pm 2.2$ & $9.3 \pm 3.1$ & 0.01 \\
\hline Average e' velocity $[\mathrm{cm} / \mathrm{s}]$ & $7.8 \pm 2.6$ & $6.9 \pm 27$ & 0.08 \\
\hline E wave velocity/average $\mathrm{e}^{\prime}$ & $8.6 \pm 1.7$ & $10.4 \pm 3.0$ & $<0.001$ \\
\hline Mitral E wave deceleration time [ms] & $182 \pm 44$ & $175 \pm 46$ & NS \\
\hline LV end diastolic dimension [mm] & $47 \pm 7$ & $46 \pm 12$ & NS \\
\hline LV end systolic dimension [mm] & $31 \pm 6$ & $30 \pm 10$ & NS \\
\hline Septal thickness [mm] & $10.9 \pm 1.7$ & $12.6 \pm 1.5$ & NS \\
\hline Posterior wall thickness [mm] & $10.9 \pm 1.6$ & $9.8 \pm 3.0$ & NS \\
\hline Systolic pulmonary artery pressure [mm Hg] & $28 \pm 7$ & $31 \pm 9$ & NS \\
\hline Right atrial pressure [mm Hg] & $5 \pm 2$ & $6 \pm 4$ & NS \\
\hline
\end{tabular}

*The $\mathrm{p}$ values for the $\chi^{2}$ test were calculated with the Fisher's exact test. The $\mathrm{p}$ value for the t-test is reported following Levene's test for equality of variance; non-significant (NS) indicates 2-tailed non-significance ( $>0.05)$; LV — left ventricular

Table 5. Linear logistic regression model.

\begin{tabular}{lcc}
\hline \multirow{2}{*}{ Correlates } & \multicolumn{2}{c}{ E/e' ratio } \\
\cline { 2 - 3 } & Beta & $\mathbf{P}$ \\
\hline Age & 0.119 & 0.123 \\
Gender & 0.169 & 0.024 \\
Diabetes & 0.129 & 0.095 \\
Hypertension & 0.179 & 0.02 \\
Peak creatine phosphokinase & 0.019 & 0.863 \\
Peak troponin & 0.118 & 0.259 \\
Left ventricular ejection fraction & 0.149 & 0.083 \\
Time to reperfusion & 0.166 & 0.023 \\
\hline
\end{tabular}

significance. Pulmonary systolic pressure is a less sensitive marker for elevated LV filling pressures than $\mathrm{E} / \mathrm{e}$ ', thus the lack of difference may be related to the small number of patients and the lack of power to detect them.

\section{Limitations of the study}

The present study has some limitations that warrant mention. Echocardiographic findings within 1-3 days of AMI may represent various states of LV loading due to heart failure, fluid management and medications admitted upon admission, such as nitrates, beta-blockers and angiotensin converting enzyme inhibitors, which may influence preload and afterload, thus possibly affecting mitral inflow measurements. Importantly, a sub-analysis of patients in whom echocardiography was performed within $24 \mathrm{~h}$ of PPCI, demonstrated similar results to that of the general cohort suggesting that early reperfusion and not other later factors is the main determinant of diastolic dysfunction post MI. In addition, age-related changes [10] as well as baseline diabetes and hypertension may result in a background level of diastolic dysfunction. Bearing these possibilities in mind, we excluded patients older than 75 years, whereby the mean age of our 
cohort was significantly lower than the mean ages of patients in previous trials that assessed E/e' in AMI $[8,9,24]$. No information was present regarding correlation of $\mathrm{E} / \mathrm{e}$ ' with $\mathrm{LV}$ end diastolic pressure, measured in cardiac catheterization, as this is not routinely performed during PPCI in our institute. We also had no information on long-term prognosis of our study participants.

\section{Conclusions}

While PPCI within $24 \mathrm{~h}$ of ischemia onset prevents significant LV systolic dysfunction in STEMI patients, even small delays in reperfusion may result in acute changes in the LV hemodynamics known to be associated with adverse outcomes.

\section{Acknowledgements}

We would like to thank Esther Eshkol, Tel Aviv Sourasky Medical Center institutional copyeditor, for editorial assistance.

This study was supported by internal departmental resources.

\section{Conflict of interest: none declared}

\section{References}

1. Nijland F, Kamp O, Karreman AJ et al. Prognostic implications of restrictive left ventricular filling in acute myocardial infarction: A serial Doppler echocardiographic study. J Am Coll Cardiol, 1997; 30: 1618-1624.

2. Moller JE, Sondergaard E, Seward JB et al. Ratio of left ventricular peak E-wave velocity to flow propagation velocity assessed by color M-mode Doppler echocardiography in first myocardial infarction: prognostic and clinical implications. J Am Coll Cardiol, 2000; 35: 363-370.

3. Moller JE, Sondergaard E, Poulsen SH et al. Pseudonormal and restrictive filling patterns predict left ventricular dilation and cardiac death after a first myocardial infarction: A serial color M-mode Doppler echocardiographic study. J Am Coll Cardiol, 2000; 36: 1841-1846.

4. Cerisano G, Bolognese L, Carrabba $\mathrm{N}$ et al. Doppler-derived mitral deceleration time: An early strong predictor of left ventricular remodeling after reperfused anterior acute myocardial infarction. Circulation, 1999; 99: 230-236.

5. Ommen SR, Nishimura RA, Appleton CP et al. Clinical utility of Doppler echocardiography and tissue Doppler imaging in the estimation of left ventricular filling pressures: A comparative simultaneous Doppler-catheterization study. Circulation, 2000; 102: $1788-1794$.

6. Nagueh SF, Middleton KJ, Kopelen HA et al. Doppler tissue imaging: a noninvasive technique for evaluation of left ventricular relaxation and estimation of filling pressures. J Am Coll Cardiol, 1997; 30: 1527-1533.

7. Sohn DW, Chai IH, Lee DJ et al. Assessment of mitral annulus velocity by Doppler tissue imaging in the evaluation of left ventricular diastolic function. J Am Coll Cardiol, 1997; 30: 474-480.

8. Hillis GS, Moller JE, Pellikka PA et al. Noninvasive estimation of left ventricular filling pressure by $\mathrm{E} / \mathrm{e}$ ' is a powerful predictor of survival after acute myocardial infarction. J Am Coll Cardiol, 2004; 43: 360-367.

9. Iwahashi N, Kimura K, Kosuge M et al. E/e' two weeks after onset is a powerful predictor of cardiac death and heart failure in patients with a first-time ST elevation acute myocardial infarction. J Am Soc Echocardiogr, 2012; 25: 1290-1298.

10. Bongiovi S, Palatini P, Macor F et al. Age and blood-pressure-related changes in left ventricular diastolic filling. J Hypertens Suppl, 1992; 10: S25-S30.

11. O'Gara PT, Kushner FG, Ascheim DD et al. 2013 ACCF/AHA guideline for the management of ST-elevation myocardial infarction: a report of the American College of Cardiology Foundation/American Heart Association Task Force on Practice Guidelines. J Am Coll Cardiol, 2012; 61: e78-e140.

12. The Thrombolysis in Myocardial Infarction (TIMI) trial. Phase I findings. TIMI Study Group. N Engl J Med, 1985; 312: 932-936.

13. Lang RM, Bierig M, Devereux RB et al. Recommendations for chamber quantification: A report from the American Society of Echocardiography's Guidelines and Standards Committee and the Chamber Quantification Writing Group, developed in conjunction with the European Association of Echocardiography, a branch of the European Society of Cardiology. J Am Soc Echocardiogr, 2005; 18: 1440-1463.

14. Schiller NB, Shah PM, Crawford M et al. Recommendations for quantitation of the left ventricle by two-dimensional echocardiography. American Society of Echocardiography Committee on Standards, Subcommittee on Quantitation of Two-Dimensional Echocardiograms. J Am Soc Echocardiogr, 1989; 2: 358-367.

15. Nagueh SF, Appleton CP, Gillebert TC et al. Recommendations for the evaluation of left ventricular diastolic function by echocardiography. Eur J Echocardiogr, 2009; 10: 165-193.

16. Lang RM, Bierig M, Devereux RB et al. Recommendations for chamber quantification. Eur J Echocardiogr, 2006; 7: 79-108.

17. Zoghbi WA, Enriquez-Sarano M, Foster E et al. Recommendations for evaluation of the severity of native valvular regurgitation with two-dimensional and Doppler echocardiography. J Am Soc Echocardiogr, 2003; 16: 777-802.

18. Kircher BJ, Himelman RB, Schiller NB. Noninvasive estimation of right atrial pressure from the inspiratory collapse of the inferior vena cava. Am J Cardiol, 1990; 66: 493-496.

19. Newby LK, Rutsch WR, Califf RM et al. Time from symptom onset to treatment and outcomes after thrombolytic therapy. GUSTO-1 Investigators. J Am Coll Cardiol, 1996; 27: 1646-1655.

20. Cannon CP, Gibson CM, Lambrew CT et al. Relationship of symptom-onset-to-balloon time and door-to-balloon time with mortality in patients undergoing angioplasty for acute myocardial infarction. JAMA, 2000; 283: 2941-2947.

21. Bradley EH, Nallamothu BK, Herrin J et al. National efforts to improve door-to-balloon time results from the door-to-balloon Alliance. J Am Coll Cardiol, 2009; 54: 2423-2429.

22. Reimer KA, Lowe JE, Rasmussen MM et al. The wavefront phenomenon of ischemic cell death. 1. Myocardial infarct size vs. duration of coronary occlusion in dogs. Circulation, 1977; 56: 786-794.

23. Hasche ET, Fernandes C, Freedman SB et al. Relation between ischemia time, infarct size, and left ventricular function in humans. Circulation, 1995; 92: 710-719.

24. Prasad SB, See V, Brown P et al. Impact of duration of ischemia on left ventricular diastolic properties following reperfusion for acute myocardial infarction. Am J Cardiol, 2011; 108: 348-354.

25. Teo SG, Yang H, Chai P et al. Impact of left ventricular diastolic dysfunction on left atrial volume and function: A volumetric analysis. Eur J Echocardiogr, 2010; 11: 38-43.

26. Abhayaratna WP, Seward JB, Appleton CP et al. Left atrial size: physiologic determinants and clinical applications. J Am Coll Cardiol, 2006; 47: 2357-2363. 